\title{
IMPLEMENTASI OLAP (ON-LINE ANALYTICAL PROCESSING) UNTUK PENGOLAHAN TRANSAKSI PENJUALAN BERBASIS WEB (STUDI KASUS: LILOLA BOUTIQUE)
}

\author{
Ni Putu Manik Ardiyanti ${ }^{1)}$ Aniek Suryanti Kusuma ${ }^{2)}$ I Kadek Budi Sandika ${ }^{3)}$ \\ Program Studi Teknik Informatika ${ }^{1)}$ 2) 3) \\ STMIK STIKOM Indonesia, Bali ${ }^{1) 2)}{ }^{2)}$ \\ manikardy@gmail.com ${ }^{1)}$ anieksuryanti@ stiki-indonesia.ac.id ${ }^{2)}$ ikbsandika@stiki-indonesia.ac.id ${ }^{3)}$
}

\begin{abstract}
Information on sales data required by the owner at Lilola Boutique as a basis for decision making and strategy. On the other hand, the large amount of transactional sales data that occurs at any time causes problems in these analyze process. To solve these problem, an OLAP (On-Line Analytical Processing) application was built. OLAP application is designed using the CodeIgniter framework which produces a fast and reliable web-based application and data warehouse as its database. To produce a good data warehouse, the Nine Step Kimball method were used. Stages of this method produced a snowflake scheme as a storage place for data warehouse. The implementation of the system design could produced the OLAP report required by Lilola Boutique. Testing the system using black box testing method that showed the performance of applications that run well. From the results of this study can be concluded that OLAP application made the process of sales transaction data analysis to produce reports as the basis of the decisionmaking process.
\end{abstract}

Keywords: Sales, OLAP, Data Warehouse, Nine Step Kimball

\begin{abstract}
ABSTRAK
Informasi mengenai data penjualan dibutuhkan oleh owner pada Lilola Boutique sebagai dasar untuk pengambilan keputusan dan penentuan strategi perusahaan. Di sisi lain, banyaknya data transaksi penjualan yang terjadi setiap harinya menyebabkan kesulitan dalam proses analisa dan pengambilan keputusan. Untuk mengatasi permasalahan tersebut, dibangun sebuah aplikasi OLAP (On-Line Analytical Processing). Perancangan aplikasi OLAP dirancang menggunakan framework CodeIgniter yang menghasilkan aplikasi berbasis web yang handal dan cepat dan data warehouse sebagai basis datanya. Untuk menghasilkan data warehouse yang baik, digunakan metode perancangan Nine Step Kimball. Tahapan metode ini menghasilkan rancangan snowflake schema sebagai tempat penampungan data warehouse. Implementasi rancangan sistem dapat menghasilkan laporan OLAP yang dibutuhkan oleh pihak Lilola Boutique. Pengujian sistem menggunakan metode black box testing yang menghasilkan unjuk kerja aplikasi yang berjalan dengan baik. Dari hasil penelitian ini dapat disimpulkan bahwa sistem aplikasi OLAP dapat membantu proses pengolahan data transaksi penjualan untuk menghasilkan laporan yang berkualitas sebagai dasar dalam pengambilan keputusan.
\end{abstract}

Kata Kunci: Penjualan, OLAP, Data Warehouse, Nine Step Kimball

\section{PENDAHULUAN}

Transaksi pada sebuah perusahaan terjadi hampir setiap waktu, tergantung dari proses bisnis yang dilakukan oleh perusahaan tersebut. Semua transaksi yang terjadi tersebut disimpan dalam sebuah sistem dan menghasilkan data dengan ukuran yang besar dan akan terus bertambah setiap harinya. Data transaksi tersebut tidak akan berguna jika hanya disimpan tanpa adanya pengolahan data demi menghasilkan informasi yang lebih bermanfaat.
Lilola Boutique merupakan perusahaan yang bergerak di bidang fashion yang menjual berbagai produk pakaian wanita. Target utama pelanggan perusahaan adalah wisatawan asing. Lilola Boutique telah menggunakan software Point of Sales Integrated System (POS IS) untuk mengakomodir transaksi operasional penjualan perusahaan. Software tersebut membantu perusahaan dalam pengolahan data penjualan. Namun, aplikasi ini masih memiliki beberapa kelemahan, terutama terbatasnya format yang disediakan oleh aplikasi POS IS 
dalam menampilkan hasil analisa. Untuk mendapat hasil analisa yang dibutuhkan oleh manajer, laporan yang dihasilkan oleh POS IS biasanya dikumpulkan, kemudian diinputkan lagi secara manual ke dalam Microsoft Excel. Hasil pengolahan data di Microsoft Excel tersebut baru dicetak dan dilaporkan kepada pimpinan perusahaan. Laporan POS IS mengandung banyak data, tetapi masih minim informasi, sehingga pengolahan data menjadi informasi memerlukan waktu lebih banyak. Padahal, informasi dari proses analisa tersebut dibutuhkan secepatnya, sebagai salah satu dasar pengambilan keputusan seperti produksi dan strategi penjualan kedepan.

Untuk mengatasi kendala tersebut, diperlukan sistem yang dapat meminimalkan waktu dalam pengolahan data untuk menghasilkan informasi yang dibutuhkan. Oleh karena data yang dihasilkan sangat banyak, dan seiring dengan perkembangan teknologi yang berbasis online, maka pengolahan data dapat menggunakan OLAP (OnLine Analitycal Processing). OLAP merupakan bentuk pemikiran bisnis yang merangkum hubungan antara pelaporan dan penggalian data [1]. OLAP secara spesifik dapat diterapkan untuk memproses laporan bisnis terkait penjualan, pemasaran, penganggaran dan peramalan. Dengan bantuan OLAP, query pada database dapat dilakukan dengan cepat, mudah dan efisien [2].

Implementasi teknologi OLAP dapat menghasilkan laporan analisa data penjualan sebagai dasar pengambilan keputusan dan penentuan strategi perusahaan [3]. Selain itu, implementasi data warehouse dan laporan dari proses OLAP, serta ditunjang dengan aplikasi dashboard mampu menyuguhkan laporan dan status penjualan secara lebih sederhana sehingga memberikan pengguna kemudahan dalam membaca laporan guna mengambil suatu keputusan [4].

Berdasarkan uraian di atas, maka OLAP diimplementasikan untuk mempermudah pengolahan data transaksi penjualan di Lilola Boutiqe. Hasil akhir dari proses analisa ini adalah sebuah laporan yang bersifat multidimensional.

\section{TINJAUAN PUSTAKA}

\section{Penjualan}

Penjualan adalah suatu usaha yang terpadu untuk mengembangkan rencana-rencana strategis yang diarahkan pada usaha pemuasan kebutuhan dan keinginan pembeli, guna mendapatkan penjualan yang menghasilkan laba [5]. Penjualan dapat dilakukan secara tunai dan ada yang dilakukan secara kredit. Penjualan tunai dilakukan apabila pembayaran telah diterima oleh penjual kemudian barang akan di berikan secara langsung kepada pembayar. Penjualan secara kredit mengakibatkan timbulnya tagihan kepada pembeli (piutang) dari transaksi penjualan barang atau jasa yang dibayarkan secara bertahap dan tidak secara langsung. Piutang dagang memiliki kecairan nomor dua setelah kas/bank. Melakukan penjualan adalah suatu kegiatan yang ditunjukkan untuk mencari pembeli, mempengaruhi, dan memberi petunjuk agar pembelian dapat menyelesaikan kebutuhannya dengan produksi yang ditawarkan serta mengadakan perjanjian mengenai harga yang menguntungkan bagi kedua pihak.

\section{Database Management System}

Database Management System (DBMS) didefinisikan sebagai sistem perangkat lunak yang memungkinkan pengguna untuk mendefinisikan, membuat, memelihara dan mengontrol akses ke database [6]. DBMS adalah lapisan perantara antara program dan data. Sebuah DBMS adalah software yang menyediakan layanan untuk mengakses database tetapi mempertahankan semua fitur yang dibutuhkan dari data. Oleh karena itu, DBMS dapat dinyatakan dalam sebuah persamaan: Basis Data + DBMS Software = Sistem Database.

\section{Data Warehouse}

Untuk melakukan pengolahan data dalam ukuran besar, perlu adanya konsistensi dalam format data. Hal ini juga akan membantu mempermudah proses analisa data. Oleh karena itu, data perlu disimpan pada media penyimpanan basis data yang memadai, seperti data warehouse. Data Warehouse dipilih karena memiliki banyak kelebihan dibanding basis data biasa, seperti sifatnya yang lebih subyektif, nonvolatile, terintegrasi, dan bersifat time variant [7].

Data warehouse adalah sekumpulan informasi yang disimpan dalam basis data yang digunakan untuk mendukung pengambilan keputusan dalam sebuah organisasi [8]. Data 
warehouse adalah proses untuk mengelola sistem pendukung keputusan, yang dapat menyesuaikan dengan kebutuhan pengguna dan merespon perubahan dari waktu ke waktu, dengan menggunakan data/record [9]. Menurut Connolly dan Begg, data warehouse merupakan sekumpulan data yang berorientasi pada subjek, terintegrasi, memiliki rentang waktu, dan tidak mudah berubah untuk mendukung proses pembuatan keputusan manajerial yang tepat [6], [10].

Arsitektur data warehouse terdiri dari sumber data, ETL, data mart dan cube. Sumber data merupakan data operasional yang disimpan dalam database, yang akan diproses (ETL) dan diintegrasikan kedalam data warehouse. Sedangkan data mart dan cube berisi data-data yang mendukung fungsi bisnis. Data mart adalah sub-set dari data warehouse yang umumnya terdiri dari sebuah subjek tunggal [11]. Jadi, data mart merupakan serangkaian data yang hanya menjelaskan satu fungsi dari operasi perusahaan.

Data yang diolah dalam data warehouse dikumpulkan dari berbagai aplikasi yang telah ada. Data tersebut kemudian diproses (divalidasi dan direstrukturisasi) lagi untuk selanjutnya disimpan dalam data warehouse. Proses tersebut terdiri dari tiga tahapan utama, yaitu ekstrak, transformasi dan loading (ETL). Proses ETL adalah alat pemecah masalah pengumpulan data dari sistem yang berbeda, dengan menyediakan kemampuan untuk memetakan dan perpindahan data dari sumber sistem ke lingkungan lain [9]. Pengumpulan data ini memungkinkan para pengambil keputusan untuk tetap dapat mengakses seluruh data dan hasil analisa tentang organisasinya saat bepergian jauh [8].

Metodologi yang dikemukakan Ralph Kimball dalam membangun data warehouse yang disebut nine-step methodology [12]. Sembilan tahapan tersebut adalah (1) pemilihan proses, (2) pemilihan sumber, (3) pengidentifikasian dan penyesuaian dimensi, (4) pemilihan fakta, (5) penyimpanan pre-calculation di tabel fakta, (6) memastikan tabel dimensi, (7) pemilihan durasi database, (8) pelacakan perubahan dari dimensi secara perlahan, (9) penentuan prioritas dan model query.

Tahapan pemilihan proses dilakukan untuk memperjelas batasan subjek apa saja yang akan dibuat dalam data warehouse. Proses ini mampu memberikan jawaban dari kebutuhan manajemen terhadap ringkasan informasi penjualan. Ringkasan tersebut dapat membantu manajemen dalam merumuskan permasalahan, memprediksi kondisi yang akan datang, melakukan evaluasi dan perencanaan, serta mengambil keputusan strategis terhadap permasalahan yang ada. Grain adalah calon fakta yang akan dianalisis. Pemilihan grain dimaksudkan untuk memutuskan record apa saja yang akan ditampilkan dari tabel fakta dalam data warehouse.

Kegiatan selanjutnya adalah mengidentifikasi dan mengkonfirmasi dimensi. Proses yang dilakukan pada tahap ini adalah membangun satu set dimensi untuk mengatur konteks pertanyaan apa saja yang nantinya akan diajukan tentang fakta-fakta yang ada dalam tabel fakta, kemudian menentukan tabel dimensi apa saja yang harus ada dan membuat data mart yang cukup jelas untuk dipahami dan digunakan.

Penentuan fakta adalah tahapan keempat, dimana pada tahap ini dipilih fakta mana saja yang dapat digunakan dalam data mart. Semua fakta harus diterjemahkan dalam bentuk elemen data, sesuai dengan grain yang telah ditentukan sebelumnya. Setiap fakta harus memiliki data yang dapat diagregasikan, agar dapat ditampilkan dalam bentuk tabel atau grafik.

Tahap kelima adalah menempatkan perhitungan awal pada tabel fakta, dimana seluruh fakta yang telah dipilih, selanjutnya harus dikaji ulang satu per satu, agar dapat diketahui apakah ada kemungkinan untuk dilakukan pra-perhitungan. Kegiatan selanjutnya yang dilakukan adalah mengembalikan fakta yang dipilih ke dalam tabel dimensi. Teks pada tabel dimensi harus mendukung permintaan intuitif dan mudah dipahami oleh pengguna.

Pemilihan durasi data histori merupakan tahapan ketujug yang memuat kebutuhan informasi dari pihak stakeholder. Pada umumnya, semakin banyak data operasional yang diringkas ke dalam data warehouse, maka akan semakin lengkap pula informasi yang bisa dihasilkan. Hal penting lainya adalah perlu diperhatikan pula tingkat akurasi yang dimiliki oleh data operasional dengan isi dan format yang ada pada data warehouse, agar data yang dipindahkan merupakan data yang benarbenar relevan dan sangat bermanfaat.

Pendeskripsian data yang tepat pada tabel dimensi harus dapat digunakan dengan data operasional yang berjalan. Untuk mengamati perubahan data pada pada tabel dimensi dapat dilakukan dengan tiga cara yaitu mengganti secara langsung pada tabel dimensi, membentuk record baru untuk setiap perubahan baru dan perubahan data yang membentuk kolom baru yang berbeda. 
Pada tahapan akhir, proses Extract, Transform and Load (ETL) dilakukan. Adapun periodenya disesuaikan dengan kebutuhan informasi dari pihak manajemen. Pada umumnya proses ini dapat dijalankan secara otomatis melalui fasilitas Data Transformation Services (DTS) yang dimiliki oleh database engine dari basis data operasional sistem.

\section{OLAP}

Implementasi teknologi OLAP dapat menghasilkan laporan analisa data penjualan sebagai dasar pengambilan keputusan dan penentuan strategi perusahaan [3]. Selain itu, implementasi data warehouse dan laporan dari proses OLAP, serta ditunjang dengan aplikasi dashboard mampu menyuguhkan laporan dan status penjualan secara lebih sederhana sehingga memberikan pengguna kemudahan dalam membaca laporan guna mengambil suatu keputusan [4].

\section{Pemodelan Dimensi}

Terdapat beberapa konsep pemodelan data warehouse pada dimensionality modeling, yaitu star schema, snowflake dan fact constellation schema. Fact constellation schema adalah skema multi dimensional yang berisikan lebih dari satu tabel fakta yang saling berbagi tabel dimensi.

Skema bintang (star schema) adalah struktur logikal yang mempunyai sebuah tabel fakta berisi data faktual yang ditempatkan di tengah, dikelilingi oleh tabel dimensi berisi data referensi (yang dapat didenormalisasi). Skema bintang mengeksploitasi karakteristik dari data faktual di mana fakta dibuat dari peristiwa yang muncul di masa lalu dan mustahil untuk berubah, dengan mengabaikan bagaimana mereka dianalisis. Skema bintang adalah teknik dasar perancangan data untuk data warehouse [11]. Struktur skema bintang adalah suatu struktur yang dapat dengan mudah dipahami dan digunakan oleh pengguna. Struktur tersebut mencerminkan bagaimana pengguna biasanya memandang ukuran-ukuran kritis mengikuti dimensi-dimensi bisnis yang ada. Skema bintang adalah sebuah desain database sederhana (yang cocok untuk query ad-hoc) yang mana data dimensi (data yang menggambarkan bagaimana cara data dikumpulkan) dipisahkan dari data fakta atau data peristiwa (data yang menggambarkan transaksi bisnis individu) [13].

Snowflake schema adalah sebuah variasi dari star schema dimana tabel dimensi tidak memuat data yang didenormalisasi. Pada skema snowflake, tabel yang berelasi pada tabel fakta hanya tabel dimensi utama, sedangkan tabel yang lain dihubungkan pada tabel dimensi utama. Model snowflake ini hampir sama seperti teknik normalisasi.

Keuntungan menggunakan model snowflake adalah pemakain space yang lebih sedikit dan update dan maintenance yang lebih mudah. Sedangkan kerugian menggunakan model ini adalah model lebih komplek dan rumit, proses query lebih lambat, dan performance yang kurang bagus

Dari ketiga skema diatas dapat disimpulkan perbedaan dari setiap skema dilihat dari tempat dan jumlah data fakta. Skema bintang adalah suatu skema yang mudah digunakan dan dipahami oleh user yang mana terdapat sebuah tabel fakta yang dikelilingi oleh beberapa tabel dimensi. Sedangkan skema snowflake merupakan pengembangan dari skema bintang namun pada snowflake tabel yang berelasi dengan tabel fakta hanya tabel dimensi utama. Pada skema fakta, terdapat beberapa tabel fakta yang saling berbagi tabel dimensi.

\section{METODOLOGI PENELITIAN}

Penelitian ini mengikuti prosedur untuk pengembangan sistem (SDLC), yang terdiri dari tahap identifikasi masalah, pengumpulan data dan analisa kebutuhan, perancangan sistem, implementasi rancangan dan pengujian sistem. Metode yang dipakai dalam pengumpulan data adalah wawancara, observasi langsung di lapangan, dan kepustakaan. Analisa kebutuhan yang dilakukan berupa analisa sistem yang telah ada, analisa kebutuhan fungsional sistem, dan kebutuhan non fungsional sistem. Tahapan selanjutnya adalah proses perancangan sistem, yang diawali dengan perencanaan proses ETL (Extract, Transform, Load). Proses ini akan menghasilkan data warehouse yang disempurnakan lagi dengan metode nine-step Kimball guna menghasilkan data warehouse yang lebih baik. Data Warehouse hasil dari proses tadi, nantinya akan dirancang menjadi aplikasi web untuk menghasilkan laporan OLAP. Setelah sistem berhasil dibuat, pengujian dilakukan dengan menggunakan metode Black Box Testing.

\section{Analisa Kebutuhan Sistem}

Gambar 1 menunjukkan alur proses dan sistem yang dirancang. Proses dimulai dari menganalisis laporan transaksi penjualan yang sudah ada dalam format .xls sesuai dengan kebutuhan yang diperlukan oleh pihak 
perusahaan LILOLA. Sumber data excel akan diproses menggunakan program Pentaho Data Integration dengan menjalankan fungsi ETL (Extract, Transform dan Loading). Database target (data warehouse) dibentuk dengan snowflake schema menggunakan penerapan metode Nine Step Kimball, sehingga menghasilkan data warehouse yang lebih baik. Dari data warehouse ini akan dibuatkan laporan OLAP untuk mendukung proses pengambilan keputusan yang strategis.

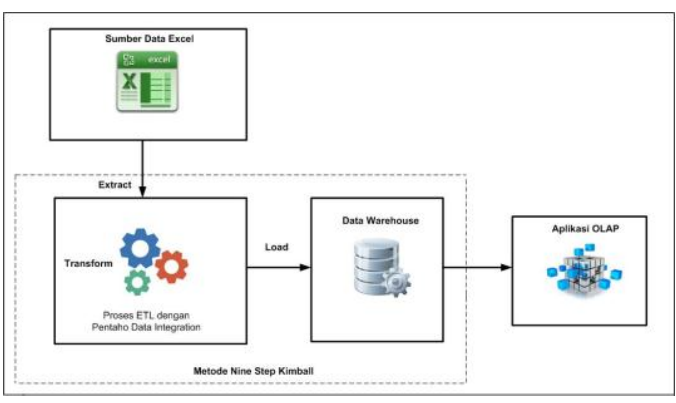

Gambar 1. Proses yang Berlangsung pada Sistem yang Dibangun

\section{Perancangan Sistem}

Use Case Diagram digunakan untuk menggambarkan proses perancangan dalam pembuatan Sistem Data Warehouse untuk Menganalisis Transaksi Penjualan Pakaian Wanita Berbasis OLAP pada LILOLA Boutique. Hanya ada satu aktor yang berperan dalam penggunaan/pengoperasian sistem, yaitu Admin, seperti ditunjukkan pada Gambar 2.

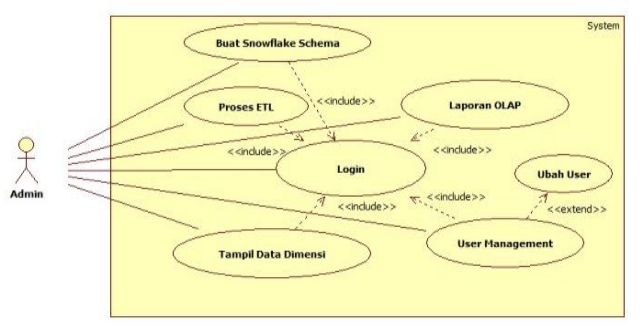

Gambar 2. Use Case Diagram

\section{Perancangan ETL}

Langkah pertama pada proses ETL adalah mengekstrak data dari sumber-sumber data, adapun sumber data dan data yang dipilih pada pembuatan sistem ini, seperti ditunjukkan Tabel 1. Langkah berikutnya adalah transformasi data, merupakan proses penyesuaian format pada data yang sudah diekstrak agar seragam dan kompatibel dengan format data pada data warehouse yang dibangun. Proses terakhir adalah loading, yaitu proses memasukkan data ke dalam data warehouse yang pada penelitian ini menggunakan DBMS MySQL.

Tabel 1. Tahap Extraction

\begin{tabular}{|l|l|}
\hline Sumber Data & Data Yang Dipilih \\
\hline Data Transaksi & 1. Data Jenis Barang \\
Penjualan & 2. Data Barang \\
& 3. Data Pembayaran \\
& 4. Data Waktu Transaksi \\
& 5. Data Toko \\
& 6. Data Penjualan \\
\hline
\end{tabular}

\section{Perancangan Data Warehouse}

Perancangan data warehouse ini menerapkan metode Nine Step Kimball [7] dengan model Snowflake Schema. Tahapan nine step Kimball dapat dijabarkan sebagai berikut:

a. Pemilihan Proses (Choosing the Process) Berdasarkan pada ruang lingkup dan ketentuan yang diberikan oleh pihak LILOLA Bali, maka terdapat beberapa proses informasi yang diperlukan, yaitu laporan analisis penjualan barang, lingkup pemasaran barang, keuntungan penjualan, dan tren persentase pertumbuhan penjualan barang.

b. Pemilihan Calon Fakta (Choosing the Grain)

Grain adalah calon fakta yang akan dianalisis. Pemilihan grain dimaksudkan untuk memutuskan record apa saja yang akan ditampilkan dari tabel fakta dalam data warehouse. Adapun grain yang dipilih pada sistem ini ditunjukkan pada Tabel 2 .

Tabel 2. Pemilihan Grain

\begin{tabular}{|l|l|}
\hline $\begin{array}{l}\text { Grain / } \\
\text { Calon Fakta }\end{array}$ & Keterangan \\
\hline Fakta & Analisis tentang informasi \\
Infomasi & penjualan barang dilihat dari \\
Penjualan & hasil laporan OLAP. \\
\hline Lingkup Fakta Penjualan : \\
1. Data Jenis Barang dan Barang \\
2. Data Jenis Pembayaran dan Waktu \\
Transaksi \\
3. Data Penjualan \\
4. Data Toko \\
\hline
\end{tabular}

c. Identifikasi dan Penyesuaian Dimensi (Identifyng and conforming the dimension) Hasil identifikasi dan penyesuaian dimensi yang terkait dengan fakta ditunjukkan pada Tabel 3.

d. Pemilihan Fakta (Choosing the Facts) 
Pada tahapan ini dilakukan penentuan fakta mana saja yang dapat digunakan dalam data mart. Semua fakta harus diterjemahkan dalam bentuk elemen data, sesuai dengan grain yang telah ditentukan sebelumnya. Fakta penjualan merupakan kumpulan berbagai informasi tentang data penjualan yang dianalisis dari dimensidimensi yang ada, yaitu Jenis Barang, Barang, Jenis Pembayaran, Waktu Terjual dan Toko

Tabel 3. Identifikasi dan Penyesuaian Dimensi

\begin{tabular}{|c|c|c|c|}
\hline $\begin{array}{l}\mathbf{N} \\
\mathbf{0}\end{array}$ & Dimensi & Keterangan & $\begin{array}{l}\text { Grain/ } \\
\text { Fakta }\end{array}$ \\
\hline 1 & $\begin{array}{l}\text { Jenis } \\
\text { Barang }\end{array}$ & $\begin{array}{l}\text { KodeJenis dan } \\
\text { NamaJenis }\end{array}$ & \multirow{5}{*}{$\begin{array}{c}\text { Penjual } \\
\text { an }\end{array}$} \\
\hline 2 & Barang & $\begin{array}{l}\text { KodeBarang, } \\
\text { KodeJenis, } \\
\text { NoBarang, } \\
\text { NamaBarang, } \\
\text { Merk, Harga dan } \\
\text { Satuan }\end{array}$ & \\
\hline 3 & $\begin{array}{l}\text { Jenis } \\
\text { Pembaya } \\
\text { ran }\end{array}$ & $\begin{array}{l}\text { KodeJenisPembay } \\
\text { aran, Waktu, } \\
\text { TotalTransaksi, } \\
\text { Tunai, Debit, } \\
\text { Kredit dan } \\
\text { Keuntungan }\end{array}$ & \\
\hline 4 & $\begin{array}{l}\text { Waktu } \\
\text { Terjual }\end{array}$ & $\begin{array}{l}\text { KodeWaktu, } \\
\text { Waktu, Tanggal, } \\
\text { Bulan, Tahun dan } \\
\text { JumlahTransaksi }\end{array}$ & \\
\hline 5 & Toko & $\begin{array}{l}\text { KodeToko, } \\
\text { NamaToko, } \\
\text { Alamat dan Telp }\end{array}$ & \\
\hline
\end{tabular}

e. Penyimpanan Pre-Calculation di Tabel Fakta (Storing Pre-calculation in the Fact Table)

Pada tahapan ini, seluruh fakta yang telah dipilih, selanjutnya harus dikaji ulang satu per satu, agar dapat diketahui apakah ada kemungkinan untuk dilakukan praperhitungan, seperti pada Tabel 4.

Tabel 4. Pre-Calculation Fakta Penjualan

\begin{tabular}{|c|l|l|}
\hline $\begin{array}{l}\text { N } \\
\text { o }\end{array}$ & Variabel & Multidimensi \\
\hline 1 & $\begin{array}{l}\text { Penjualan } \\
\text { Barang }\end{array}$ & $\begin{array}{l}\text { sum(fact_penjualan.J } \\
\text { umlahBarang) }\end{array}$ \\
\hline 2 & $\begin{array}{l}\text { Lingkup } \\
\text { Pemasaran }\end{array}$ & $\begin{array}{l}\text { sum(fact_penjualan. } \\
\text { KodeToko) }\end{array}$ \\
\hline 3 & Keuntungan & $\begin{array}{l}\text { sum(fact_penjualan. } \\
\text { KodeJenisPembayara }\end{array}$ \\
\hline
\end{tabular}

\begin{tabular}{|l|l|l|}
\hline & & n) \\
\hline 4 & Tren & sum(fact_penjualan. \\
& Penjualan & KodeWaktu) \\
\hline
\end{tabular}

f. Memastikan Tabel Dimensi (Rounding Out the Dimension Table)

Pada tahapan ini, kegiatan yang dilakukan adalah mengembalikan fakta yang dipilih ke dalam tabel dimensi. Menambahkan sebanyak mungkin deskripsi teks pada dimensi. Deskripsi tersebut harus intuitif dan dapat dimengerti oleh user.

g. Pemilihan Durasi Database (Choosing the Duration of the Database)

Pemilihan durasi data histori yang dimiliki dapat dilakukan sesuai dengan kebutuhan informasi dari pihak stakeholder. Pada umumnya, semakin banyak data operasional yang diringkas ke dalam data warehouse, maka akan semakin lengkap pula informasi yang bisa dihasilkan. Hal penting lainya adalah perlu diperhatikan pula tingkat akurasi yang dimiliki oleh data operasional dengan isi dan format yang ada pada data warehouse, agar data yang dipindahkan merupakan data yang benar-benar relevan dan bermanfaat. Rentang waktu pengumpulan data dari Desember 2016 hingga Oktober 2017.

Tabel 5. Kesesuaian Fakta Penjualan

\begin{tabular}{|l|l|l|l|l|}
\hline $\begin{array}{l}\text { N } \\
\text { o }\end{array}$ & Nama Field & $\begin{array}{l}\text { Tipe } \\
\text { Data }\end{array}$ & $\begin{array}{l}\text { Panja } \\
\text { ng }\end{array}$ & $\begin{array}{l}\text { Stat } \\
\text { us }\end{array}$ \\
\hline 1 & KodePenjualan & $\begin{array}{l}\text { Varc } \\
\text { har }\end{array}$ & 10 & $\begin{array}{l}\text { Sesu } \\
\text { ai }\end{array}$ \\
\hline 2 & KodeBarang & $\begin{array}{l}\text { Varc } \\
\text { har }\end{array}$ & 10 & $\begin{array}{l}\text { Sesu } \\
\text { ai }\end{array}$ \\
\hline 3 & KodeWaktu & $\begin{array}{l}\text { Varc } \\
\text { har }\end{array}$ & 10 & $\begin{array}{l}\text { Sesu } \\
\text { ai }\end{array}$ \\
\hline 4 & $\begin{array}{l}\text { KodeJenisPemb } \\
\text { ayaran }\end{array}$ & $\begin{array}{l}\text { Varc } \\
\text { har }\end{array}$ & 10 & $\begin{array}{l}\text { Sesu } \\
\text { ai }\end{array}$ \\
\hline 5 & KodeToko & $\begin{array}{l}\text { Varc } \\
\text { har }\end{array}$ & 10 & $\begin{array}{l}\text { Sesu } \\
\text { ai }\end{array}$ \\
\hline 6 & NamaBarang & $\begin{array}{l}\text { Varc } \\
\text { har }\end{array}$ & 50 & $\begin{array}{l}\text { Sesu } \\
\text { ai }\end{array}$ \\
\hline 7 & JumlahBarang & $\begin{array}{l}\text { Integ } \\
\text { er }\end{array}$ & 5 & $\begin{array}{l}\text { Sesu } \\
\text { ai }\end{array}$ \\
\hline 8 & Total Bayar & $\begin{array}{l}\text { Doub } \\
\text { le }\end{array}$ & 10 & $\begin{array}{l}\text { Sesu } \\
\text { ai }\end{array}$ \\
\hline
\end{tabular}

Tabel 6. Kesesuaian Dimensi Jenis Barang

\begin{tabular}{|l|l|l|l|l|}
\hline N & Nama & Tipe & Panjan & Statu \\
\hline
\end{tabular}




\begin{tabular}{|l|l|l|l|l|}
\hline o & Field & Data & g & s \\
\hline 1 & KodeJenis & $\begin{array}{l}\text { Varcha } \\
\text { r }\end{array}$ & 10 & Sesuai \\
\hline 2 & $\begin{array}{l}\text { NamaJeni } \\
\text { s }\end{array}$ & $\begin{array}{l}\text { Varcha } \\
\text { r }\end{array}$ & 50 & Sesuai \\
\hline
\end{tabular}

\begin{tabular}{|l|l|l|l|l|}
\hline & & le & & ai \\
\hline
\end{tabular}

h. Melacak Perubahan Dimensi Secara Perlahan (Tracking Slowly Changing Dimensions)

Pendeskripsian data yang tepat pada tabel dimensi harus dapat digunakan dengan data operasional yang berjalan. Untuk mengamati perubahan data pada pada tabel dimensi dapat dilakukan dengan tiga cara yaitu mengganti secara langsung pada tabel dimensi, membentuk record baru untuk setiap perubahan baru dan perubahan data yang membentuk kolom baru yang berbeda. Untuk implementasi data warehouse pada Lilola, maka dipilih cara kedua yaitu jika ada perubahan data, maka akan dibentuk record baru pada tabel dimensi.

i. Penentuan Prioritas dan Model Query (Deciding the Query priorities and the Query Mode)

Langkah yang terakhir adalah penentuan model query untuk menghasilkan laporan OLAP dimana hasilnya akan ditampilkan pada aplikasi berbasis web yang sudah memiliki kualitas data yang baik karena sudah melalui proses ETL.

\section{Perancangan OLAP}

Proses yang berlangsung pada metode nine step Kimball menghasilkan model multidimensi Snowflake Schema. Adapun snowflake schema pada sistem ini seperti ditunjukkan pada Gambar 3. Laporan OLAP (Online Analitical Processing) akan ditampilkan berupa dashboard halaman web. Laporan OLAP ini akan menampilkan hasil analisis yang dibutuhkan oleh pihak LILOLA dalam mendukung proses pengambilan

Tabel 9. Kesesuaian Dimensi Jenis Pembayaran

\begin{tabular}{|l|l|l|l|l|}
\hline $\begin{array}{l}\text { N } \\
\text { o }\end{array}$ & Nama Field & $\begin{array}{l}\text { Tipe } \\
\text { Data }\end{array}$ & $\begin{array}{l}\text { Panja } \\
\text { ng }\end{array}$ & $\begin{array}{l}\text { Stat } \\
\text { us }\end{array}$ \\
\hline 1 & $\begin{array}{l}\text { KodeJenisPemb } \\
\text { ayaran }\end{array}$ & $\begin{array}{l}\text { Varc } \\
\text { har }\end{array}$ & 10 & $\begin{array}{l}\text { Sesu } \\
\text { ai }\end{array}$ \\
\hline 2 & Waktu & Date & - & $\begin{array}{l}\text { Sesu } \\
\text { ai }\end{array}$ \\
\hline 3 & TotalTransaksi & $\begin{array}{l}\text { Doub } \\
\text { le }\end{array}$ & 10 & $\begin{array}{l}\text { Sesu } \\
\text { ai }\end{array}$ \\
\hline 4 & Tunai & $\begin{array}{l}\text { Doub } \\
\text { le }\end{array}$ & 10 & $\begin{array}{l}\text { Sesu } \\
\text { ai }\end{array}$ \\
\hline 5 & Debit & $\begin{array}{l}\text { Doub } \\
\text { le }\end{array}$ & 10 & $\begin{array}{l}\text { Sesu } \\
\text { ai }\end{array}$ \\
\hline 6 & Kredit & $\begin{array}{l}\text { Doub } \\
\text { le }\end{array}$ & 10 & $\begin{array}{l}\text { Sesu } \\
\text { ai }\end{array}$ \\
\hline 7 & Keuntungan & Doub & 10 & Sesu \\
\hline
\end{tabular}

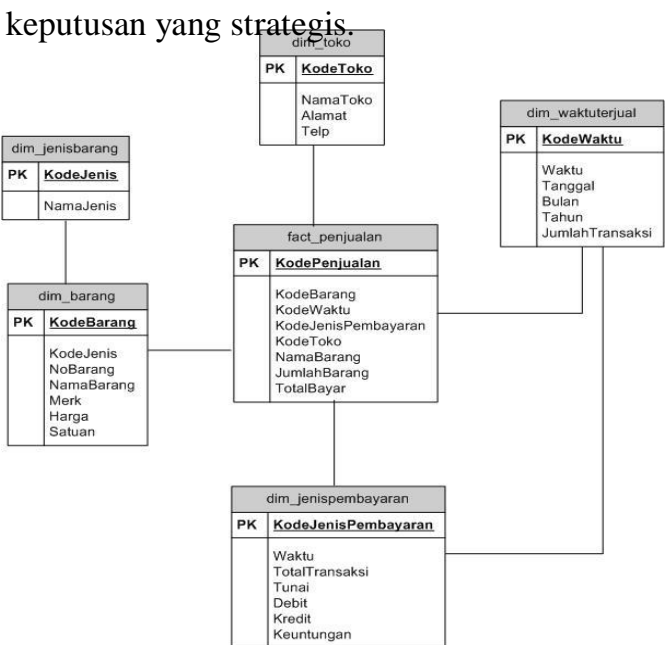




\section{Gambar 3. Snowflake Schema}

\section{Rancangan Pengujian Sistem}

Pengujian sistem dimaksudkan untuk memastikan perangkat lunak yang dibuat dapat berjalan sesuai harapan untuk menghasilkan perangkat berkualitas (software quality) Pendekatan black box testing digunakan untuk mengevaluasi kebutuhan fungsional dari kinerja proses Aplikasi OLAP yang dirancang. Pada pengujian ini akan dilibatkan tester sebanyak 5 orang yang memiliki kemampuan dibidang programming. Adapun aspek yang diuji seperti ditunjukkan Tabel 10.

Tabel 10. Komponen Sistem yang Diuji

\begin{tabular}{|c|c|c|c|}
\hline $\begin{array}{l}\mathrm{N} \\
\mathrm{O}\end{array}$ & $\begin{array}{l}\text { Fun } \\
\text { gsi }\end{array}$ & $\begin{array}{l}\text { Skenario } \\
\text { Pengujian }\end{array}$ & $\begin{array}{c}\text { Hasil Proses } \\
\text { yang diharapkan }\end{array}$ \\
\hline \multirow[t]{4}{*}{1} & $\begin{array}{l}\log \\
\text { in }\end{array}$ & $\begin{array}{l}\text { Username } \\
\text { dan } \\
\text { password } \\
\text { dikosongkan }\end{array}$ & $\begin{array}{l}\text { Sistem akan } \\
\text { menolak akses } \\
\text { login dan } \\
\text { menampilkan } \\
\text { notifikasi }\end{array}$ \\
\hline & & $\begin{array}{l}\text { Mengisi } \\
\text { username } \\
\text { tapi } \\
\text { password } \\
\text { dikosongkan } \\
\text {, atau } \\
\text { sebaliknya }\end{array}$ & $\begin{array}{l}\text { Sistem akan } \\
\text { menolak akses } \\
\text { login dan } \\
\text { menampilkan } \\
\text { notifikasi }\end{array}$ \\
\hline & & $\begin{array}{l}\text { Mengisi } \\
\text { username } \\
\text { benar dan } \\
\text { password } \\
\text { salah atau } \\
\text { sebaliknya }\end{array}$ & $\begin{array}{l}\text { Sistem akan } \\
\text { menolak akses } \\
\text { login dan } \\
\text { menampilkan } \\
\text { notifikasi }\end{array}$ \\
\hline & & $\begin{array}{l}\text { Mengisi } \\
\text { username } \\
\text { dan } \\
\text { password } \\
\text { dengan } \\
\text { benar }\end{array}$ & $\begin{array}{l}\text { Sistem menerima } \\
\text { akses login dan } \\
\text { kemudian } \\
\text { langsung } \\
\text { menampilkan } \\
\text { form aplikasi } \\
\text { utama halaman } \\
\text { admin. }\end{array}$ \\
\hline \multirow[t]{2}{*}{2} & $\begin{array}{l}\text { Me } \\
\text { nu } \\
\text { dat } \\
\text { a } \\
\text { war } \\
\text { eho } \\
\text { use }\end{array}$ & $\begin{array}{l}\text { Memilih } \\
\text { submenu } \\
\text { Membuat } \\
\text { Snowflake } \\
\text { Schema }\end{array}$ & $\begin{array}{l}\text { Muncul dialog } \\
\text { Snowflake } \\
\text { schema sudah } \\
\text { terbentuk, dan } \\
\text { pada database } \\
\text { terbentuk tabel- } \\
\text { tabel yang } \\
\text { dimaksud. }\end{array}$ \\
\hline & & $\begin{array}{l}\text { Memilih } \\
\text { submenu }\end{array}$ & $\begin{array}{l}\text { Program } \\
\text { memanggil }\end{array}$ \\
\hline
\end{tabular}

\begin{tabular}{|c|c|c|c|}
\hline & & Proses ETL & $\begin{array}{l}\text { Pentaho untuk } \\
\text { dijalankan. }\end{array}$ \\
\hline & & $\begin{array}{l}\text { Memilih } \\
\text { submenu } \\
\text { Tabel } \\
\text { Dimensi dan } \\
\text { Fakta }\end{array}$ & $\begin{array}{l}\text { Sistem } \\
\text { menampilkan } \\
\text { Tabel Dimensi } \\
\text { dan Fakta. }\end{array}$ \\
\hline \multirow[t]{4}{*}{3} & $\begin{array}{l}\text { Me } \\
\text { nu } \\
\text { lap } \\
\text { ora } \\
\text { n } \\
\text { OL } \\
\text { AP }\end{array}$ & $\begin{array}{l}\text { Submenu } \\
\text { Laporan } \\
\text { Analisis } \\
\text { Penjualan } \\
\text { Barang }\end{array}$ & $\begin{array}{l}\text { Muncul grafik } \\
\text { dan tabel laporan } \\
\text { analisis } \\
\text { penjualan } \\
\text { barang. }\end{array}$ \\
\hline & & $\begin{array}{l}\text { Submenu } \\
\text { Laporan } \\
\text { Analisis } \\
\text { Lingkup } \\
\text { Pemasaran } \\
\text { Barang }\end{array}$ & $\begin{array}{l}\text { Muncul grafik } \\
\text { dan tabel laporan } \\
\text { analisis analisis } \\
\text { lingkup } \\
\text { pemasaran } \\
\text { barang }\end{array}$ \\
\hline & & $\begin{array}{l}\text { Submenu } \\
\text { Laporan } \\
\text { Analisis } \\
\text { Laba Rugi }\end{array}$ & $\begin{array}{l}\text { Muncul tabel } \\
\text { laporan analisis } \\
\text { laba rugi. }\end{array}$ \\
\hline & & $\begin{array}{l}\text { Submenu } \\
\text { Laporan } \\
\text { Analisis } \\
\text { Laba Rugi }\end{array}$ & $\begin{array}{l}\text { Muncul tabel } \\
\text { laporan analisis } \\
\text { laba rugi. }\end{array}$ \\
\hline
\end{tabular}

\section{IMPLEMENTASI}

\section{Halaman Dashboard}

Berikut tampilan dashboard program aplikasi OLAP, menu pertama yaitu kelola data warehouse, terdiri dari beberapa submenu yaitu: pembuatan snowflake schema, proses ETL, lalu tabel dimensi dan fakta.

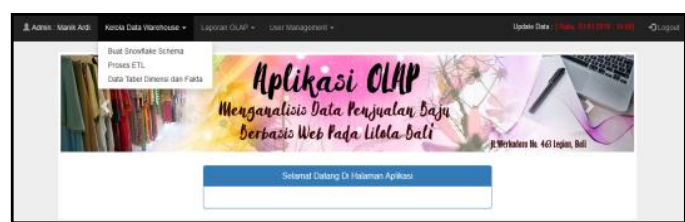

Gambar 4. Dashboard Aplikasi OLAP

\section{Laporan OLAP}

Menu laporan OLAP terdiri dari empat submenu Laporan Analisis. Yaitu laporan analisis penjualan barang, laporan analisis lingkup pemasaran barang, laporan analisis laba rugi, dan tren persentase pertumbuhan penjualan barang.

Laporan analisis penjualan barang menampilkan grafik dan tabel dari barang yang berhasil terjual dalam setiap bulannya. User 
dapat memilih range waktu pertahun yang ingin ditampilkan. Saat pertama dijalankan, program akan menampilkan grafik dan tabel dari tahun terakhir dari data yang masuk ke dalam sistem (default). Grafik dan tabel dapat dilihat pada Gambar 5.

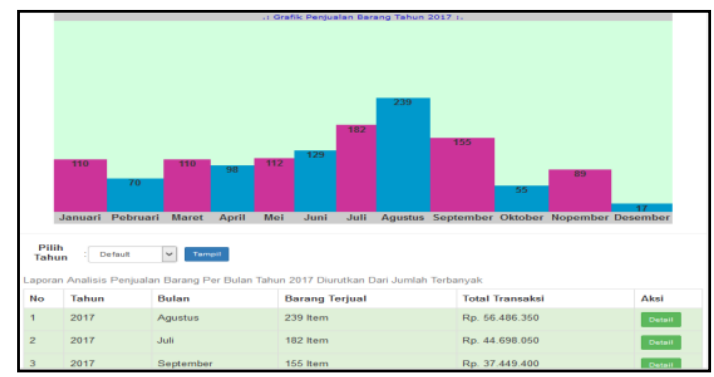

Gambar 5 Tampilan Laporan Analisis Penjualan Barang

Laporan Tren Persentase Pertumbuhan Penjualan Barang menampilkan tabel dari banyaknya barang terjual setiap bulannya. Persentase pertumbuhan didapat dari membandingkat banyak item terjual bulan bersangkutan dengn bulan sebelumnya. Saat pertama dijalankan, program akan menampilkan tabel dari tahun terakhir dari data yang masuk ke dalam sistem (default). Tabel dapat dilihat pada Gambar 6.

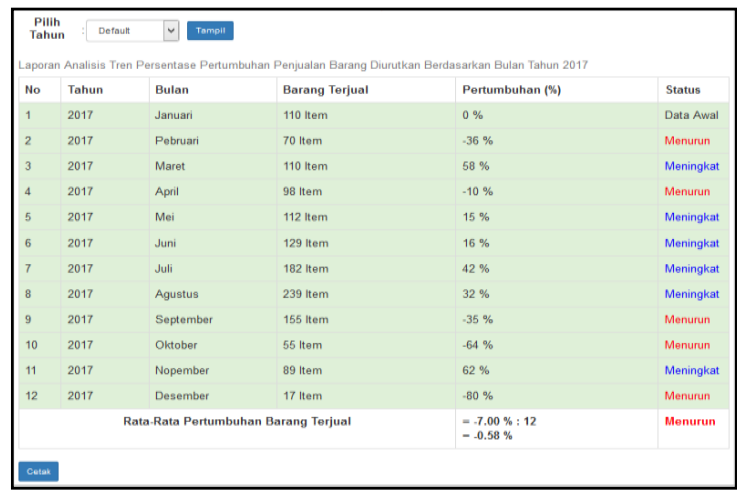

Gambar 6.Tampilan Laporan Tren Persentase Pertumbuhan Penjualan Barang

\section{Hasil Pengujian Sistem}

Tabel 10. Hasil Pengujian Sistem

\begin{tabular}{|c|l|c|c|c|c|c|}
\hline \multirow{2}{*}{$\begin{array}{c}\text { N } \\
\text { o }\end{array}$} & Aspek Pengujian & \multicolumn{5}{|c|}{ Pasil Pengujian } \\
\cline { 2 - 7 } & $\mathbf{1}$ & $\mathbf{2}$ & $\mathbf{3}$ & $\mathbf{4}$ & $\mathbf{5}$ \\
\hline \multirow{2}{*}{$\mathbf{1}$} & $\begin{array}{l}\text { Username dan } \\
\text { password } \\
\text { dikosongkan }\end{array}$ & $\mathrm{O}$ & $\mathrm{O}$ & $\mathrm{O}$ & $\mathrm{O}$ & $\mathrm{O}$ \\
$\mathrm{K}$ & $\mathrm{K}$ & $\mathrm{K}$ & $\mathrm{K}$ & $\mathrm{K}$ \\
\hline
\end{tabular}

\begin{tabular}{|c|c|c|c|c|c|c|}
\hline & $\begin{array}{l}\text { Mengisi username } \\
\text { tapi password } \\
\text { dikosongkan, atau } \\
\text { sebaliknya }\end{array}$ & $\begin{array}{l}\mathrm{O} \\
\mathrm{K}\end{array}$ & $\begin{array}{l}\mathrm{O} \\
\mathrm{K}\end{array}$ & $\begin{array}{l}\mathrm{O} \\
\mathrm{K}\end{array}$ & $\begin{array}{l}\mathrm{O} \\
\mathrm{K}\end{array}$ & $\begin{array}{l}\mathrm{O} \\
\mathrm{K}\end{array}$ \\
\hline & $\begin{array}{l}\text { Mengisi } \text { username } \\
\text { benar dan } \\
\text { password salah } \\
\text { atau sebaliknya }\end{array}$ & $\begin{array}{l}\mathrm{O} \\
\mathrm{K}\end{array}$ & $\begin{array}{l}\mathrm{O} \\
\mathrm{K}\end{array}$ & $\begin{array}{l}\mathrm{O} \\
\mathrm{K}\end{array}$ & $\begin{array}{l}\mathrm{O} \\
\mathrm{K}\end{array}$ & $\begin{array}{l}\mathrm{O} \\
\mathrm{K}\end{array}$ \\
\hline & $\begin{array}{l}\text { Mengisi username } \\
\text { dan password } \\
\text { dengan benar }\end{array}$ & $\begin{array}{l}\mathrm{O} \\
\mathrm{K}\end{array}$ & $\begin{array}{l}\mathrm{O} \\
\mathrm{K}\end{array}$ & $\begin{array}{l}\mathrm{O} \\
\mathrm{K}\end{array}$ & $\begin{array}{l}\mathrm{O} \\
\mathrm{K}\end{array}$ & $\begin{array}{l}\mathrm{O} \\
\mathrm{K}\end{array}$ \\
\hline & $\begin{array}{l}\text { Memilih submenu } \\
\text { Membuat } \\
\text { Snowflake } \\
\text { Schema }\end{array}$ & $\begin{array}{l}\mathrm{O} \\
\mathrm{K}\end{array}$ & $\begin{array}{l}\mathrm{O} \\
\mathrm{K}\end{array}$ & $\mathrm{O}$ & $\begin{array}{l}\mathrm{O} \\
\mathrm{K}\end{array}$ & $\begin{array}{l}\mathrm{O} \\
\mathrm{K}\end{array}$ \\
\hline 2 & $\begin{array}{l}\text { Memilih submenu } \\
\text { Proses ETL }\end{array}$ & $\begin{array}{l}\mathrm{O} \\
\mathrm{K}\end{array}$ & $\begin{array}{l}\mathrm{O} \\
\mathrm{K}\end{array}$ & $\begin{array}{l}\mathrm{O} \\
\mathrm{K}\end{array}$ & $\begin{array}{l}\mathrm{O} \\
\mathrm{K}\end{array}$ & $\begin{array}{l}\mathrm{O} \\
\mathrm{K}\end{array}$ \\
\hline & $\begin{array}{l}\text { Memilih submenu } \\
\text { Tabel Dimensi } \\
\text { dan Fakta }\end{array}$ & $\begin{array}{l}\mathrm{O} \\
\mathrm{K}\end{array}$ & $\mathrm{O}$ & $\mathrm{O}$ & $\begin{array}{l}\mathrm{O} \\
\mathrm{K}\end{array}$ & $\begin{array}{l}\mathrm{O} \\
\mathrm{K}\end{array}$ \\
\hline & $\begin{array}{l}\text { Submenu Laporan } \\
\text { Analisis } \\
\text { Penjualan Barang }\end{array}$ & $\begin{array}{l}\mathrm{O} \\
\mathrm{K}\end{array}$ & $\begin{array}{l}\mathrm{O} \\
\mathrm{K}\end{array}$ & $\begin{array}{l}\mathrm{O} \\
\mathrm{K}\end{array}$ & $\begin{array}{l}\mathrm{O} \\
\mathrm{K}\end{array}$ & $\begin{array}{l}\mathrm{O} \\
\mathrm{K}\end{array}$ \\
\hline 3 & $\begin{array}{l}\text { Submenu Laporan } \\
\text { Analisis Lingkup } \\
\text { Pemasaran } \\
\text { Barang }\end{array}$ & $\begin{array}{l}\mathrm{O} \\
\mathrm{K}\end{array}$ & $\begin{array}{l}\mathrm{O} \\
\mathrm{K}\end{array}$ & $\begin{array}{l}\mathrm{O} \\
\mathrm{K}\end{array}$ & $\begin{array}{l}\mathrm{O} \\
\mathrm{K}\end{array}$ & $\begin{array}{l}\mathrm{O} \\
\mathrm{K}\end{array}$ \\
\hline & $\begin{array}{l}\text { Submenu Laporan } \\
\text { Analisis Laba } \\
\text { Rugi }\end{array}$ & $\begin{array}{l}\mathrm{O} \\
\mathrm{K}\end{array}$ & $\begin{array}{l}\mathrm{O} \\
\mathrm{K}\end{array}$ & $\begin{array}{l}\mathrm{O} \\
\mathrm{K}\end{array}$ & $\begin{array}{l}\mathrm{O} \\
\mathrm{K}\end{array}$ & $\begin{array}{l}\mathrm{O} \\
\mathrm{K}\end{array}$ \\
\hline & $\begin{array}{l}\text { Submenu Laporan } \\
\text { Analisis Laba } \\
\text { Rugi }\end{array}$ & $\begin{array}{l}\mathrm{O} \\
\mathrm{K}\end{array}$ & $\begin{array}{l}\mathrm{O} \\
\mathrm{K}\end{array}$ & $\begin{array}{l}\mathrm{O} \\
\mathrm{K}\end{array}$ & $\begin{array}{l}\mathrm{O} \\
\mathrm{K}\end{array}$ & $\begin{array}{l}\mathrm{O} \\
\mathrm{K}\end{array}$ \\
\hline
\end{tabular}

\section{Pembahasan}

Berdasarkan hasil pengujian menggunakan black box testing, dapat menganalisis hasil pengujian, yaitu : Aplikasi OLAP untuk menganalisis data transaksi penjualan baju berbasis web yang dibangun dapat membantu menganalisa data transaksi penjualan, memberikan informasi sesuai fakta dan menyajikan informasi yang mudah dibaca dan bersifat multidimensional. Berdasarkan hasil pengujian, semua aspek yang diuji menunjukkan hasil yang valid. Dengan demikian, dapat dinyatakan bahwa semua komponen telah menunjukkan fungsi sesuai dengan perencanaan.

\section{SIMPULAN}

Dari pelaksanaan penelitian ini, mulai dari pengumpulan data, perancangan, pembuatan, hingga pengujian sistem dapat ditarik kesimpulan bahwa Program aplikasi OLAP untuk menganalisis data transaksi penjualan pada Lilola Boutique dibangun dengan tahapan pengembangan data warehouse melalui proses ETL (Extract, Transform dan Loading) 
menggunakan tool Pentaho dimana data disimpan pada database OLAP yang pembentukannya melalui tahapan Nine Step Kimball.Program dashboard aplikasi OLAP untuk menganalisis transaksi penjualan ini dibangun dengan menggunakan framework PHP Codeigniter yang dapat menampilkan hasil laporan OLAP yang dibutuhkan pada Lilola Boutique. Dari hasil pengujian dengan menggunakan metode black box testing, unjuk kerja dari aplikasi yang dirancang berjalan dengan baik dan sesuai dengan fungsinya, serta laporan OLAP yang dihasilkan dapat membantu proses pengambilan keputusan strategis pada Lilola Boutique.

\section{DAFTAR PUSTAKA}

[1] 'Online analytical processing Wikipedia bahasa Indonesia, ensiklopedia bebas," 2013. [Online]. Available:

https://id.wikipedia.org/wiki/Online_an alytical_processing. [Accessed: 02Aug-2018].

[2] A. Kadir and T. C. Triwahyuni, Pengantar Teknologi Informasi, Edisi Revisi, II. Yogyakarta: Andi Publisher, 2013.

[3] I. Tresnawati and E. Susilowati, "Implementasi Teknologi OLAP pada Sistem Pengolahan Data Penjualan," in Seminar Nasional Sains dan Teknologi, 2014.

[4] D. Pratama, "Implementasi Data warehouse dan Business Intelegence untuk memonitor penjualan Sales Group pada PT. XYZ," Universitas Indonesia, 2013.

[5] Kotler, Perkembangan Sosial Budaya dan Ekonomi. Yogyakarta: Andi Publisher, 2006.

[6] E. R. Chopra, Database Management System (DBMS): A Practical Approach. Ram Nagar: S. Chand, 2013.

[7] W. H. Inmon, Building the Data Warehouse, 4th ed. Indianapolis: Wiley Publishing, Inc., 2005.

[8] A. Handojo and S. Rostianingsih, "Pembuatan Data Warehouse Pengukuran Kinerja Proses Belajar Mengajar Di Jurusan Teknik Informatika Universitas Kristen Petra," J. Inform., vol. 5, no. 1, pp. 53-58, 2004.

[9] M. J. A. Berry and G. S. Linoff, Data Mining Techniques for Marketing,
Sales, and Customer Relationship Management, Second Edi. Indianapolis: Wiley Publishing, Inc., 2004.

[10] H. Antonius and E. Widjaja, "Data Warehouse pada Rumah Sakit," in Seminar Nasional Aplikasi Teknologi (SNATI), 2010, pp. 68-72.

[11] S. Darudiato, "Perancangan Data Warehouse Penjualan Untuk Mendukung Kebutuhan Informasi Eksekutif Cemerlang Skin Care," semnasIF, vol. 2010, no. semnasIF, pp. 350-359, 2010.

[12] C. S. R. Prabhu, Data Warehouse Concept, Tehniques, Product \& Applications. New Delhi: Pratience Half of India, 2006.

[13] J. A. Hoffer, M. B. Prescott, and F. R. McFadden, Modern Database Management, 7th ed. Upper Saddle River: N.J Pearson/ Prentice Hall, 2007.

[14] N. T. S. Saptadi and H. C. Marwi, "Hospital Function Services Model by Data Warehouse," J. Technol. Res. Inf. Syst. Eng., vol. 1, no. 2, pp. 16-25, 2014. 